Artificial gametes

\section{Artificial gametes: new paths to parenthood?}

\section{A J Newson, A C Smajdor}

A number of recent papers have described the successful derivation of egg and sperm precursor cells from mouse embryonic stem cells-so-called "artificial" gametes. Although many scientific questions remain, this research suggests numerous new possibilities for stem cell research and assisted reproductive technology, if a similar breakthrough is achieved with human embryonic stem cells. The novel opportunities raised by artificial gametes also prompt new ethical questions, such as whether same-sex couples should be able to access this technology to have children who are genetically related to them both.

\section{THE CREATION OF "ARTIFICIAL" GAMETES}

Over the past two years, a number of papers have been published detailing the first successful attempts at differentiating mouse embryonic stem cells into egg $^{1}$ and sperm ${ }^{2}$ precursor cells. Previously, researchers had used embryonic stem cells to generate tissues such as brain, liver, and pancreatic cells, but not germ cells of any kind. Production of gamete precursor cells was achieved initially through allowing stem cell lines to differentiate more or less randomly, but recent research has focused on identifying the precise ways in which differentiation into gametes can be precipitated and controlled. These breakthroughs make it seem likely that ongoing research on human stem cells will yield similar possibilities, ${ }^{3}$ raising questions over the practicalities of what might be achieved with such "artificial" gametes. In turn, the novel opportunities presented by artificial gametes raise a number of ethical concerns.

The initial breakthrough, namely the obtaining of egg cells from mouse stem cells, was achieved by means of relatively simple science. Rather than coaxing stem cells to develop into eggs using complicated cocktails of growth factors, researchers adopted standard cell culture conditions, but grew the cells at higher density than usual. ${ }^{3-6}$ Growing the cells in this way led to the formation of ovary-like cell aggregates, which (when separated and stimulated with the hormone gonadotrophin) produced eggs. ${ }^{3}$ The eggs do seem to function in the same way as "real" gametes: they have undergone meiosis (a halving of the number of chromosomes; an essential prerequisite to fertilisation) and express specific genes at appropriate times. One might have thought that the sheer size differential between eggs_-which are relatively large-and the much smaller stem cells from which they are derived might pose a problem. However, a proportion of the oocytes (egg precursor cells) derived from stem cell lines does fall within the size range of natural oocytes $(50-70 \mu \mathrm{m}){ }^{1}$ Still, many failed to reach this, while others far exceeded it, indicating a wider range of variability than might be expected in "real" gametes.

In the case of sperm formation, cultured embryonic mouse stem cells formed clusters known as embryoid bodies, within which researchers located what appeared to be primordial germ cells. To prove that these cells really had become spermatocytes, scientists exposed them to retinoic acid, which stimulates gametes to divide, but causes embryonic stem cells to stop dividing. The cells in question fulfilled the scientific expectation by dividing in the manner of normal gametes. ${ }^{7}$

Work carried out by a separate group of researchers has also resulted in the successful development of immature sperm which, when injected into mouse oocytes, developed into blastocysts and early embryos. ${ }^{8}$ Blastocysts formed in this way maintained the expected ratios of male to female, and carried the requisite diploid chromosome complement. To date, however, there have been no reports of any of such embryos being brought to term.

Clearly, there is much work to be done before fully functioning gametes obtained from human stem cells become available. However, it seems feasible that this will eventually be achieved, as the consensus among researchers is that there is no reason why it should not work with other mammalian species. ${ }^{3}$

\section{SURPRISING FINDINGS}

Some rather surprising details have emerged from the research findings outlined above. For example, it appears that if kept in culture, the egg precursor cells tend to form parthenogenic blastocysts $^{9}$ (that is, they begin to develop into embryos despite not having been fertilised ${ }^{1011}$ ). It is unlikely that parthenogenic blastocysts would ever be viable, ${ }^{11}$ and thus it has been suggested that research performed on blastocysts obtained in this way would circumvent the ethical concerns which arise from research on "normal" embryos. However, this may not be of much practical use: researchers actually prefer working with viable embryos, as they are more likely to be successful in generating stem cell lines.

Despite the peculiarity of the idea that embryos could grow from unfertilised eggs, it should be mentioned that parthenogenesis is a relatively normal phenomenon affecting eggs kept in culture. In this respect, therefore, the "artificial" eggs were actually behaving in the same way as "real" ones might, under the same conditions. ${ }^{1}$

Additionally, contrary to what might have been expected, oocytes have been derived from both female and male stem cell lines. However, while this may initially appear bizarre, Hübner et al point out that: "...it is not surprising that the derivation of oocytes and blastocyst-like structures could be accomplished with both female and male ES cells. In the absence of appropriate $S R Y$ expression in the gonads, male primordial germ cells enter the female pathway and often undergo the first step of oogenesis, entering meiotic arrest at prophase one." ${ }^{\prime 1}$ It seems, then, that the potential to develop into egg precursors is a latent property of all male germ cells given certain conditions. The same is not true of female embryonic stem cells: these can only give rise to eggs, as the $\mathrm{Y}$ chromosome is essential for the formation of sperm.

\section{POTENTIAL RESEARCH APPLICATIONS}

There are many possible applications for gametes obtained from stem cells. If sperm and egg cells created using this method do develop normally and existing human stem cell lines can be cultured in the same way, a renewable source of gametes could be established, which in turn could be used to generate a plentiful resource of embryos and stem cells for research purposes. ${ }^{4}{ }^{10} 12$ The current dearth of available gametes, particularly eggs, is clearly already a serious issue affecting the pace of stem cell research, because the proportion of stem cell lines developed to eggs used is 
extremely small. For example, the stem cell breakthrough achieved by Korean researchers in February 2004 involved the creation of only one stem cell line from 242 donor eggs. ${ }^{13}$ It is likely that successful production of human stem cell gametes would boost research enormously and go some way towards realising the potential of stem cell therapies for the treatment of cancers, diabetes, Parkinson's disease, strokes, and other illnesses.

There are also a number of illnesses which particularly affect the germ cells, and it is likely that the ability to study the development of artificial gametes in vitro will provide insights into illnesses which particularly affect the germ cells. Indeed, Hübner et al speculate that research on artificial gametes could "contribute to a better understanding of the regulation of spontaneous ovarian teratocarcinogenesis and the molecular mechanism by which genes such as $c$ mos block the second meiotic metaphase arrest".

Research involving artificial gametes could also lead to an increased understanding of genomic imprinting. ${ }^{6}{ }^{14}$ It is well known that the chemical suppressors on our chromosomes affecting gene expression differ depending on whether we inherited the particular chromosome from our mother or father..$^{15}$ Currently, a significant safety concern with reproductive cloning is that the imprinting pattern on chromosomes is suboptimal for healthy embryo development, as the cell does not have its imprinting "reprogrammed" to allow genes vital to embryo development to be switched on. ${ }^{3}$ However, the number of defects in the offspring of cloned animals is much lower, suggesting the gametes produced by a clone have their imprinting "corrected". The production of an egg from a cloned embryo could mimic this "correction" process, thus reducing the risks involved in reproductive cloning. ${ }^{3}$

However, while it is important to note that increased availability of gametes might well further research in all of the areas mentioned above, it is of course true that a lack of available gametes is not the only factor affecting the pace of research in this area. There are also many ethical, religious, and political objections to the use of human embryos and gametes in research. It has been suggested that the use of artificial gametes-and of embryos created by the fertilisation of such artificial gametes-might be regarded as a way of alleviating some of these concerns. $^{35} 10121617$ However one question which will inevitably arise is whether there is an ethical difference between (a) destroying an embryo generated from artificial gametes in order to obtain stem cells, and (b) destroying an embryo donated for research for the same purpose. After all, if children born from artificial gametes would share the same moral status as any other children-and the suggested use of artificial gametes for reproductive purposes implies that they would-it is hard to see why it should be morally preferable to perform research on the embryos which could become such children, than to perform research on any other embryos.

Another ethical question relating to research on artificial gametes is the possibility that it could facilitate new targeted eugenic technologies. This prospect has already been mooted by one commentator who suggests that it "opens the door to creating 'designer' eggs from scratch", ${ }^{12}$ while another suggests that research on artificial gametes could facilitate "...manipulation of the germ line...". ${ }^{18}$ As researchers are already developing mechanisms to manipulate genes in stem cells, it may be possible for selected genes to be substituted. These changes would then be "inherited" in any gametes generated (and would be reproduced in persons born from these gametes). If this were indeed to become possible, the usual arguments surrounding both germ line gene therapy and genetic enhancement would apply.

\section{A NEW TREATMENT FOR INFERTILITY?}

Infertility is a major and growing problem in the developed world. Various factors contribute to this, including declining sperm counts, the increasing age of first time parents, the rising incidence of sexually transmitted diseases such as Chlamydia, and an increase in the incidence of polycystic ovary syndrome (PCOS). It was suggested at the Human Genetics Organisation meeting in Cancún, Mexico in May 2003 that using gametes obtained from human embryonic stem cells would be a feasible way of offering treatment to infertile couples who are unable to have genetically related children. ${ }^{19}$ For example, if "made to order" eggs were obtained from an embryonic clone of an infertile woman, couples would be able to use IVF to have a child genetically related to them both, without the need for donor gametes. ${ }^{5} 6$

At present, there is such a severe deficit of donor gametes in the United Kingdom that it has been characterised as approaching "catastrophic" levels. ${ }^{20}$ It is likely that this situation will be exacerbated by recent legislation stipulating that as of April 2005, children born as a result of gamete donation will have the right to seek their donors' identities. ${ }^{21}$ Existing donors have been requesting that their samples in storage be destroyed in order to avoid the prospect of future children seeking out their genetic parents, while fewer and fewer new donors are coming forward. This being the case, the availability of "artificial" gametes is likely to be eagerly welcomed by those who are affected by the current deficit.

There would, of course, be issues relating to the costs of providing artificial gametes. But it is not immediately obvious that such costs would outweigh the current costs involved in recruiting gamete donors, screening them, storing gametes, and so on. Additionally, there will be costs involved in legislating to lift donor anonymity and providing the practical means for donor-conceived children to locate their "parents". Already, there has been some talk of the desirability of introducing payments for gamete donors, in the hope of increasing the supply. This will further increase the overall costs of obtaining and supplying such gametes. ${ }^{22}$

The other issue to consider in relation to the problem of donor gametes is the burden that egg donation imposes on women. There have been fears of the emergence of an "egg donor underclass", consisting of women from poor socioeconomic backgrounds who submit to repeated egg donation procedures to make money or gain access to fertility treatment-raising issues of physical harm and coercion. ${ }^{12}$ The availability of artificial gametes might well be regarded as a solution to this ethical concern.

However, perhaps it is worth mentioning that although the availability of artificial gametes might benefit women by relieving them of the necessity to undergo painful and invasive egg harvesting procedures, it would also inevitably increase the medicalisation of conception and pregnancy. Pregnancies brought about by means of artificial gametes would necessarily require IVF techniques which are in themselves burdensome for the women who undergo them.

\section{NEW PATHS TO PARENTHOOD?}

The possibility of obtaining gametes from human embryonic stem cells suggests some challenging new opportunities in reproductive technologies, enabling people who might not necessarily be regarded as being "infertile" to have children in entirely new ways. For example, male couples might be able to use this research to create children genetically related to both parties, although they would still have to rely on a woman to gestate the child. Female couples could not benefit from this 
technology as spermatozoa cannot be generated in the absence of a Y chromasome. However, artificial gamete technology could also enable women who have passed the menopause to produce eggs and bear children who are genetically related to them. At present, postmenopausal fertility treatments have to rely on donor gametes.

Another possibility is that any individual man could produce offspring of which he would be the only genetic parent. This would involve obtaining eggs and sperm from an embryonic clone of the prospective "parent". Such a procedure hovers uneasily on the boundary between reproductive and therapeutic cloning. However any child born as a result of such techniques would not be genetically identical with the man from whose stem cells the gametes had been obtained. This is because when germ cells are formed, the genetic information is "reshuffled", so while the offspring would be likely to bear a family resemblance to its "parent", it would not be a clone in the sense of sharing an identical genome. The child's genetic makeup would also be influenced by mitochondrial DNA from the donor of the initial egg.

Clearly, such revolutionary ways of being able to create children will raise ethical questions. For example, Douglas Johnson of the US based National Right to Life Committee has expressed concern that the technology could lead to large scale human embryo farms. ${ }^{12}$ It might also be feared that children would be psychologically damaged by the knowledge that they had been born as a result of using artificial gametes. Perhaps it is also worth asking: if gametes can be termed "artificial", might children born of these gametes likewise be seen as artificial in some sense?

CAN A STEM CELL BE A PARENT? Collectively, these potential applications of artificial gamete creation raise many important questions. For example, how should we assess this technology in light of current conceptions of parenthood and the moral relationships within families? Will being genetically related to two parents of the same sex fundamentally alter the experience of childhood? Will a man whose DNA is contained in the egg be recognised as a biological "mother"? Should the line between fathers and mothers remain distinct $?^{12}$ This heralds a new challenge to medical ethics: to contemplate how these innovations might affect concepts of kinship, parental roles, and the relationships between parents and children.

J Med Ethics 2005;31:184-186.

doi: 10.1136/jme.2003.004986

\section{Authors' affiliations}

A J Newson, A C Smajdor, Medical Ethics Unit, Imperial College London, London, UK

Correspondence to: $\operatorname{Dr}$ A J Newson, Medical Ethics Unit, Imperial College London, 3rd Floor, Reynolds Building, St Dunstan's Road, London W6 8RP UK; a.newson@imperial.ac.uk

Received 23 May 2003

In revised form 23 May 2003

Accepted for publication 20 August 2003

\section{REFERENCES}

1 Hübner K, Fuhrmann G, Christenson LK, et al. Derivation of oocytes from mouse embryonic stem cells. Science 2003;300:1251-6.

2 Westphal SP. Stem cells can become 'normal sperm'. NewScientist.com News Service, 7 May 2003. Available at http://

www. newscientist.com/news/ news. jp? $\mathrm{id}=$ ns99993700 (accessed 20 May 2003).

3 Westphal SP. The next IVF revolution? New Scientist 2003;178:3.

4 BBC News Online. Eggs 'created' from stem cells, 1 May 2003. Available at http:// news.bbc.co.uk/1/hi/health/2993023.stm (accessed 16 May 2003).

5 Westphal SP. Embryonic stem cells turned into eggs. New Scientist.com News Service, 1 May 2003. Available at http:// www.newscientist.com/news/ news.jsp?id = ns99993688 (accessed 16 May 2003).
6 Clarke T. Eggs made from embryos. Nature Science Update 2 May 2003. Available at http:// www.nature.com/nsu/030428/030428-17.html (accessed 16 May 2003).

7 Vogel G. Embryonic stem cells scientists make sperm in a dish. Science 2003;302:1875.

8 Geijsen N, Horoschak M, Kim K, et al. Derivation of embryonic germ cells and male gametes from embryonic stem cells. Nature 2004;427:148-54.

9 Azim S. How to make eggs and sperm. Nature 2004;427: 106-7.

10 Wade N. Pennsylvania researchers turn stem cells to egg cells. The New York Times 2 May, 2003:28.

11 Rougier N, Werb Z. Parthenogenesis in mammals. Mol Reprod Dev 2001;59:468-74.

12 Weiss R. In laboratory, ordinary cells are turned into eggs. The Washington Post 2 May, 2003:1

13 Westphal SP. Cloned human embryos are stem cell breakthrough. New Scientist.com News Service, 12 February 2004. Available at hitp:// www.newscientist.com/news/ news.jsp?id=ns99994667 (accessed 14 Dec 2004).

14 Pearson H. DNA re-write could allay cloning fears. Nature Science Update 29 April 2003. Available at http://www.nature.com/nsu/ 030428/030428-6.html (accessed 16 May 2003).

15 Jaenisch R, Bird A. Epigenetic regulation of gene expression: how the genome integrates intrinsic and environmental signals. Nat Genet 2003:33(Suppl):245-54.

16 O'Mathúna DP. Cloning twist clouds ethical complexities. The Centre for Bioethics and Human Dignity 13 June 2003. Available at http:// www.cbhd.org/resources/cloning/ omathuna_2003-06-13_print.htm\#fn 1 laccessed 14 Dec 2004)

17 Testa G, Harris J. Ethical aspects of ES cellderived gametes. Science 2004;305:1719.

18 Kadereit, S. Nuclear transfer (nt)ES cells: A first step towards therapy? International Society for Stem Cell Research 2004. Available at http:// www.isscr.org/scientists/TOM/Mar04.htm (accessed 14 Dec 2004).

19 Bhattacharya S. Stem cells can end infertility, say IVF pioneers. New Scientist.com News Service, 24 July 2004. Available at http:// www.newscientist.com/news/ news.jsp? id = ns99993980 (accessed 14 Dec 2004).

20 Netdoctor. co.uk. Sperm donor children will win right to trace father. 22 January 2004. Available at http://www2.netdoctor.co.uk/news/ index. $\operatorname{asp} ? \mathrm{y}=2004 \& \mathrm{~m}=1 \& \mathrm{~d}=22$ (accessed 14 Dec 2004)

21 UK Department of Health. Anonymity to be removed from future sperm, egg and embryo donors. 21 January 2004. Available at http:// www.dh.gov.uk/PublicationsAndStatistics/ PressReleases/PressReleasesNotices/ $\mathrm{F}_{\mathrm{s}}$ / en?CONTENT_ID = 4070524\&chk $=i L T|| \% 2 B$ (accessed 14 Dec 2004).

22 BBC News Online. Egg and sperm donor cash proposal, 11 November 2004. Available at http://news.bbc.co.uk/1/hi/health/ 4002829.stm (accessed 14 Dec 2004) 